\begin{abstract}
Iranica
Abstracta Iranica Revue bibliographique pour le domaine irano-aryen

Volume 34-35-36 | 2017

Comptes rendus des publications de 2011-2013
\end{abstract}

\title{
Matthew P. Canepa. The Two Eyes of the Earth. Art and Ritual of Kingship between Rome and Sasanian Iran
}

\section{Philip Huyse}

\section{OpenEdition}

\section{Journals}

Édition électronique

URL : http://journals.openedition.org/abstractairanica/42278

DOI : 10.4000/abstractairanica.42278

ISSN : 1961-960X

Éditeur :

CNRS (UMR 7528 Mondes iraniens et indiens), Éditions de l'IFRI

Référence électronique

Philip Huyse, "Matthew P. Canepa. The Two Eyes of the Earth. Art and Ritual of Kingship between Rome and Sasanian Iran », Abstracta Iranica [En ligne], Volume 34-35-36 | 2017, document 25, mis en ligne le 30 juillet 2017, consulté le 02 octobre 2020. URL : http://journals.openedition.org/abstractairanica/ 42278 ; DOI : https://doi.org/10.4000/abstractairanica.42278

Ce document a été généré automatiquement le 2 octobre 2020.

Tous droits réservés 


\title{
Matthew P. Canepa. The Two Eyes of the Earth. Art and Ritual of Kingship between Rome and Sasanian Iran
}

\author{
Philip Huyse
}

\section{RÉFÉRENCE}

Matthew P. Canepa. The Two Eyes of the Earth. Art and Ritual of Kingship between Rome and Sasanian Iran. Berkeley / Los Angeles / Londres, University of California Press, 2009, XX +425 p. (The Transformation of the Classical Heritage, XLV)

1 Si l'étude des relations romano-sassanides a connu un important renouveau sur les trente dernières années, c'est essentiellement les sources documentaires (littéraires et épigraphiques) qui ont été mises en avant pour une analyse approfondie. Les domaines de la numismatique, de la sigillographie et de la papyrologie ont certes été tout aussi innovants sinon plus encore, mais elles touchent en très grande partie à des questions internes à l'empire sassanide et sont moins concernés par des réflexions sur les influences mutuelles entre l'Occident et l'Iran. En revanche, l'héritage matériel - à l'exception des bas-reliefs sassanides - est jusqu'ici largement resté en dehors des discussions et c'est précisément la tâche à laquelle s'est attelé le jeune historien de l'art américain Matthew Canepa dans cette monographie issue d'une thèse de doctorat à l'Université de Chicago en 2004. Signalons au passage un important article de sa main intitulé "Technologies of Memory in Early Sasanian Iran: Achaemenid Sites and Sasanian Identity" dans l'American Journal of Archaeology 114, 2010, 563-596, où il a analysé les techniques artistiques et architecturales employées par les premiers Sassanides Ardašīr I ${ }^{\text {er }}$ et Šābuhr I ${ }^{\text {er }}$ pour forger " leur » histoire du passé et s'insérer dans une longue tradition en la réinterprétant à leur manière.

2 Après une brève introduction (p. 1-5) et un premier chapitre (p. 7-33) non dépourvu d'intérêt dans lequel l'A. esquisse l'art et les lieux rituels liés au pouvoir à Rome 
(Byzance/Constantinople) et en Iran sassanide, il examine successivement le contexte historique précédant l'époque sassanide (chap. 3, p. 34-52) ainsi que le règne de Šābuhr $\mathrm{I}^{\mathrm{er}}$, avec une place particulière accordée à l'influence de l'art romain dans les reliefs sassanides (chap. 4, p. 53-78). Au chapitre suivant (chap. 5, p. 79-99), l'A. interprète - de manière tout à fait convaincante - l'arc de triomphe de (Maximien) Galère à Thessalonique comme la réponse romaine aux reliefs de victoire sassanides, très en vogue à cette époque. Le chap. 6 (p. 100-121) traite de la symbolique exprimant le triomphe au IVe s., à Rome/Byzance comme en Iran. Au chap. 7 (p. 122-153), c'est le protocole diplomatique qui est passé au crible. Les contacts diplomatiques intensifs des derniers siècles de la dynastie sassanide avaient conduit à un rapprochement dans le cérémoniel protocollaire des deux cours (byzantine et sassanide), qui a trouvé une répercussion dans l'art, dont les différentes formes d'expression sont disséquées dans le chap. 8 (p. 154-187). Le dernier chap. 9 (p. 188-223) est consacré au développement des insignes royaux. Le bref épilogue offre un - trop court - résumé des empreintes laissées par l'art sassanide en Asie comme en Europe (p. 224-25). Alors que les chapitres descriptifs sur l'histoire sassanide ne résument et répètent essentiellement des choses déjà fort bien connues, c'est incontestablement dans les chapitres " artistiques " que Canepa est au mieux et où il est en mesure de démontrer son originalité, en attirant l'attention sur des détails jusqu'ici négligées ou oubliées afin d'apporter un nouveau regard sur ces deux puissances majeures de l'Antiquité tardive et du Haut Moyen Âge, non sans raison comparées à deux yeux illuminant la Terre par l'historien byzantin Théophylacte Simocatès.

\section{AUTEURS}

\section{PHILIP HUYSE}

EPHE 